\title{
Study of Decision-making Skill of +2 Students in Relation to their Self-Regulation, Self-Efficacy and Satisfaction with School
}

\author{
Shivraj Singh ${ }^{1 *}$, Malvinder Ahuja ${ }^{2}$ \\ ${ }^{1}$ Lecturer Political Science, ${ }^{2}$ Retired Professor and Head \\ ${ }^{1}$ Department of Punjab School Education, Chandigarh, Panjab, India \\ ${ }^{2}$ Dept of education, Panjab University, Chandigarh, Panjab, India
}

\begin{abstract}
This study was conducted to investigate effects of single variables (A. self efficacy, B. self regulation and C. satisfaction of students with school) on skill of decision making of twelfth grade students and also their two order and three order interaction effects on decision making. Null hypotheses were framed for each effect. The sample comprised of 515 students chosen from representative CBSE affiliated secondary schools of district Roopnagar, Punjab. An ex post facto design of the study led to an analysis of data through a statistical technique of $3 \times 3 \times 3$ ANOVA substantiated by t-test.

A brief summary of findings was as follows:

Main effects of all three independent variables A, B, C, were found to be significant at the .01 level of confidence indicating strong influence of each of these variables on skill of decision making. Out of the three two order interactions, only AxC was found to be significant at the .05 level of confidence and those of AXB and BXC were not found to be significant even at the .05 level of confidence. This indicated that AXC interacts to result into differences in means scores of decision making of various combination groups due to AXC only. The three order interaction of AXBXC was also found to be significant at the .05 level of confidence, which led to conclude that combination groups due to this interaction effect resulted in differences in decision making by twelfth graders.

Keywords: Decision Making, Satisfaction, Self efficacy, Self regulation.

Journal of Teacher Education and Research (2019). DOI: 10.36268/JTER/1424
\end{abstract}

\section{INTRODUCTION}

Life skills are behaviors used appropriately and responsibly in the management of personal affairs. They are a set of human skills acquired via teaching or direct experience that are used to handle problems and questions commonly encountered in daily human life. The subject varies greatly depending on social norms and community expectations. Enumeration and categorization of various classifications of life skills are as under:-

- The WHO, 1997 categorizes the life skills into the three components;

- Cognitive-domain, emphasizing 1. Skill of Creative thinking, 2. Skill of Critical thinking

- Affective-domain; emphasising; 1. Skill of Self Awareness, 2.skill of Empathy

- Psychomotor Domain; 1. Skill of Interpersonal relationship and communication, 2. Skill of decision making and problemsolving, 3. Skill of Coping with emotion and coping with stress

- The Samaritans and Kelly support group (1999) has identified seven life skills by the $4 \mathrm{~h}$ program as being essential for productive and healthy lives. These are;

- Creative thinking

- Decision making

- Acquiring knowledge

- Responsibility

- Communication

- Understanding self

- Getting along with others
Corresponding Author: Shivraj Singh, Department of Punjab School Education, Chandigarh, Panjab, India, E-mail: shivdhillon83@yahoo. co.in

How to cite his article: Singh, S. and Ahuja, M. (2019). Study of Decision-making Skill of +2 Students in Relation to their SelfRegulation, Self-Efficacy and Satisfaction with School. Journal of Teacher Education and Research, 14(2): 3-16:

Source of support: Nil

Conflict of interest: None

In the present investigation Skill of decision making has been taken to be studied

\section{The Skill of decision Making}

Decision making skill is that thinking which results in the choice among alternative courses of action (Taylor, 1965). Decision making is to opt for appropriate and suitable decision i.e., course, job, where to live and how to spend money, etc. from a number of choices. Developing self-responsibility and independence in the student is the main aim of the learning skill of decision-making. According to Myers Isabel Briggs (1962), a person's decisionmaking process depends to a significant degree on their cognitive style. The dimensions of cognition style are thinking and feeling, extroversion and introversion; Judgment and perception, and sensing and intuition. According to Toda (1979) a decision process consists of all the sub-processes pertaining to the selection of a course of action or a plan and to its execution. 'Satisficing', coined

(0) The Author(s). 2019 Open Access This article is distributed under the terms of the Creative Commons Attribution 4.0 International License (http://creativecommons. org/licenses/by/4.0/), which permits unrestricted use, distribution, and non-commercial reproduction in any medium, provided you give appropriate credit to the original author(s) and the source, provide a link to the Creative Commons license, and indicate if changes were made. The Creative Commons Public Domain Dedication waiver (http://creativecommons.org/publicdomain/zero/1.0/) applies to the data made available in this article, unless otherwise stated. 
by combining satisfactory and sufficient, is also the strategy for many small decisions in which the first satisfactory alternative is chosen rather than the best alternative. Maximax means 'maximize the maximums, ' which focuses on choosing the alternative based on their maximum possible pay off after evaluation.

\section{Characteristics of Decisions Making}

- Goal-oriented: Decisions are made to achieve certain goals by bridging the gap between the present and desired position. The good decision helps to attain the desired goal.

- Choice or selection: decision making involves the most appropriate course of action among two or more alternatives.

- Continuous process: Decision-making exercise is a regular job of an individual.

- Intellectual process: decision making is an outcome of deliberations, reasoning, judgments, and evaluation. Intuition and experiences are also included in it.

- Dynamic process: Various techniques are used for decision making according to the nature of the problem.

- Situational: One may make a particular decision in one situation and opposite in another.

\section{Components of Decisions Making}

- Decision environment: Environment is defined as the collection of information, alternative values, and preferences available for the decision to be taken. Both information and alternatives are constrained because the timeand effort to gqaqqqqqwqaawaaAain information or identify alternatives are limited. The decisions must be made within this constrained environment.

- Effects of quantity on decision making: Selective use of information is required to make a good decision because overloaded information creates mental fatigue, which results in slower or poor quality decisions and delays which could impair the effectiveness of the decision.

- Decision streams: Most of the decision involves a choice from a group of pre-selected alternatives made available to us or previous decision that one individual has made which enables us to make future decisions and prevents other future decisions.

\section{Factors Influencing decision Making}

Juliusson, Karlsson, and Garling (2005) indicated past decisions influence the decisions people make in the future because when something positive happens from a decision, people are more likely to decide similarly, given a similar situation. On the other way, people tend to avoid repeating past mistakes (Sagi, and Friedland, 2007). Although past experiences have an impact on the decision-making process and the decisions made but these decisions are not necessarily the best decisions. In addition to past experiences, several cognitive biases influence decisions making. Cognitive biases are thinking patterns based on observation and generalization that may lead to memory errors, inaccurate judgments, and faulty logic (Evans, Barston, and Pollard, 1983).

The steps of the decision-making process are as follows:

- Identify the problem

- Gather information about the problem and your options

- List your options

- Write down things.

- Enlist the things

- Compare

Decision making is a nonlinear, recursive process i. e. most decisions are made by moving back and forth between the choice of criteria and the identification of alternatives. Therefore, decision making is a reasoning process which can be rational or irrational and can be based on explicit assumptions.

\section{Self Regulation}

Self-Regulation is the ultimate goal in learning by Bandura (1988). It is the conscious use of strategies for encoding-activity, organization, and elaboration without direction from others. Self-Regulation refers to the analysis of the causes of behavior. In other words, the behavior is self-determined and self-initiated, or it arises as a result of interpersonal/intrapersonal forces that include an element of pressure.

\section{Characteristics of the Self-regulated Learners}

Self-regulated learners use cognitive and metacognitive strategies and are intrinsically motivated by Zimmerman (1994, 2002). Cognitive strategies are defined as the behaviors and thought in which students are engaged in while studying. Meta-cognitive processes involve learners' ability to plan, schedule, and evaluate their learning progress. Motivational processes indicate that learners are self-motivated and willing to take responsibility for their successes or failures. Behavior refers to the characteristics of the strategies that students utilize to optimize learning (Zimmerman and Martinez-Pons, 1986, 1988). Bulter and Winne (1995) proposed that self-regulation is a learning style for students, comprising of strong abilities like setting goals for developing knowledge and choosing balancing strategies against unwanted situations by determining goals, defined self-regulation as "the process whereby students activate and sustain cognitions, behaviors, and effect which are systematically oriented toward attainment of their goals." He proposed that self-regulated learning has a sixcomponent model: content domain, cognitive strategies, cognitive regulatory strategies, metacognitive knowledge, and motivational belief, motivational strategy use, and motivational regulatory techniques (Bockaerts, 1997). Academic self-regulation has been studied in traditional classrooms as a means of understanding how successful students adapt their cognition, motivation, and behavior to improve learning. The central ideas underlying self-regulation are motivation and learning strategies that students utilize to achieve their learning goals.

\section{Self Efficacy}

Self-efficacy is defined as a self-evaluation of one's competence to successfully execute a course of action necessary to reach desired outcomes (Bandura, 1977, 1982, 1986). According to Albert Bandura's social cognitive theory, self-efficacy is the perception or judgment of one's ability to perform a certain action successfully. Studies have shown that perceived self-efficacy is a significant determinant of performance that operates partially independent of underlying skills. In educational concerns, there are three different levels at which perceived self-efficacy operates as an important contributor to academic development. Students' beliefs in their efficacy to regulate their own learning and to master academic activities determine their aspirations, level of motivation. It is a multidimensional construct that varies according to the domain of demands (Zimmerman 2000), and therefore, it must be evaluated at a level that is specific to the outcome domain (Bandura, 1986 Pajares, 1996). Thus in academic settings, one should measure academic self-efficacy rather than generalized self-efficacy, where academic self-efficacy refers to students' confidence in their ability to carry out such academic tasks as preparing exams and writing 
Study of Decision-making Skill of +2 Students in Relation to their Self-Regulation, Self-Efficacy and Satisfaction with School

term papers. A large meta-analysis of studies of self-efficacy in academic environments concluded that the most specific academic self-efficacy indices had the strongest effect on academic outcomes, while the more generalized measures were less closely associated (Multon, Brown, and Lent, 1991). General self-efficacy measure was not found to be predictive of any college outcomes (Ferrari and Parker, 1992; Lindley and Borgen, 2002), while academic self-efficacy has been consistently shown to predict grades and persistence in college.

Bandura (1997) hypothesized that students from their selfefficacy by selecting and interpreting information from four primary sources, the most powerful of which is the result of their own previous performance or mastery experience. Students also build their self-efficacy belief through the vicarious experience of observing the actions of others. It is for this reason that models can play a significant role in the development of self-efficacy. The third source of self-efficacy information comes from the social persuasions that individuals receive from others. Students often depend on parents, teachers, and peers to provide evaluative feedback, judgments, and appraisal about their academic performance. Finally, self-efficacy beliefs are informed by emotional and physiological states such as arousal, anxiety, mood, and fatigue. Self-efficacy is task-specific and is not conceptualized as global personality characteristics. For example, an individual may have high self-efficacy at solving math problems but low self-efficacy at giving public speeches (Pajares 1996).

\section{Self-efficacy Beliefs can Influence People in Several Important Ways}

The beliefs can affect the environment that people choose because most people prefer the environment in which they feel competent to avoid those in which they feel inadequate. Self-efficacy can also affect how individuals face failure and handle adversity. Academic self-efficacy refers to subjective convictions that one can successfully carry out given academic tasks at designated levels (Schunk, 1991). Task value is defined as an incentive to engage in academic activity, which represents a composite construct encompassing perceived importance, usefulness, and interest (Wigfield and Eccles, 1992). Perceptions of self-efficacy and task value often are correlated positively, and both have been proven effective predictors of a variety of academic outcomes (Multon, Brown, and Lent, 1991). Self-efficacy beliefs also are affected by attributions that students make for their success and failure. Attributions of success to stable factors such as high ability have the greatest impact on the increase in subsequent self-efficacy (Schunk, 1984; Schunk and Gunn, 1986).

\section{Student Satisfaction}

The measurement of student satisfaction can be useful to secondary school students as well as the institution of their teaching, to help them to pinpoint their strengths and identify areas for improvement. Satisfaction ratings go beyond teaching assessments with a narrow focus, including broader aspects of the student learning experiences, to grasp the complexity of that learning experience. It is not enough to know the degree to which students are satisfied; it is important to understand the factors that contribute to student satisfaction.

\section{Teacher}

Teachers who take the time to develop positive relationships with their students will see improvement in their students both academically, behaviorally, and emotionally Stipek (2006)

\section{Fellow Student}

Peer acceptance and friendships are distinct constructs and contribute to youth development. Peer acceptance has been shown to be associated with greater feelings of belonging (Brown and Lohr, 1987) and fewer behavioral problems in youth (Coie, Terry, Lenox, Lochman, and Hyman, 1995)

\section{School Work}

Students are a major stakeholder group in the school to work on the initiative; therefore, consulting with them about their perceptions about the impact of school to work program participation is an important aspect of school work evaluation.

\section{Student Activities}

Supporters of high school sport programs argue that sport participation improves students achievement motivation (Casey, 1989; Parker and Johnson, 1981), improves students grades, keeps them in school, raises their educational aspirations (Melnick, Sabo, and Vanforsen, 1992) helps them appreciate health, exercise, and fitness, helps them learn about themselves and learn to handle adversity, and helps them experience teamwork and sportsmanship (Rasmussen, 2000).

\section{Student Discipline}

Every effort is to be made to see that the child understands the reason for correction and the purpose of measures taken

\section{Decision making Opportunities}

The relation between decision making opportunity in the classroom and student motivation behavior has been investigated extensively (Dechorms, 1968, 1976; Epstein, 1981; Richter and Tjosvold, 1980; Wang and Stiles, 1976). In-general, increased opportunity for decision making is associated with a more positive attitude toward self, teachers, and classrooms.

\section{School Buildings, Supplies, and Upkeeps}

Loukas and Robinson (2004) found that the most significant aspects of school climate that influenced students' school conduct and depressive symptoms included cohesion, friction or competition amongst students, and overall satisfaction with students in the building. Mijanovich and Weitzman (2003) discovered that student's level of perceived school disorder had the most impact on their negative feelings of school safety.

\section{Communication}

Students feel that communication channels in the schools are inadequate and sluggish. A study by Williams (1964) revealed that parents, students, and teachers look upon the administration as a friendly meeting place for all those participating in the school program, the nerve center of the school, the office should be adequately equipped with an intercom, bulletin boards and a conference room in which personal interaction can be facilitated. Thus, communication is a process crucial to the central idea of work. Communication can also be used to improve satisfaction by adjusting student's perceptions of issues.

\section{Significance of the Problem}

Life skills are the skills that enable to succeed in the environment in which we live. Life skills are those competencies that help people 
function well in the environment in which they live and improve the quality of life and general well being. The International Bureau of Education (IBE, 2006) derives its understanding from the UNESCO's Dalor report Learning: The treasure within (1996) are learning to know, learning to do, learning to be and learning to live together stated that basic education for all, both formal and Informal must be based on these four Pillars of education. These four pillars can only be achieved when there is the proper development of all the skills that are helpful to live with dignity. These skills are called life skills. These skills help to deal effectively with the demands and challenges of modern society. Today's children are facing numerous challenges i.e., different career choices, addictions, broken relationships, natural disasters, a highly competitive work spot, and more. Life skills-based education is being adopted the work over to help children, imbibe attitudes, behavioral patterns, and skills necessary to cope with the growing challenges. The need for life skills education is highlighted directly and indirectly in the convention of the child's right and a number of international recommendations.

This current scenario of the education system in India found that the development of life skills is an important part of personality development, which can be beneficial for all young adults. Life skills are the core competencies an individual possesses that enable them to cope with the difficulties in life. For this purpose, the investigator made a humble attempt to explore the effects of self-regulation, self-efficacy, and satisfaction of students with a school on the skill of decision Making. The researcher is keen to understand how self-regulation, self-efficacy, and satisfaction with school impact students learning of skill of decision Making.

\section{Delimitations of The Study}

The present study was limited to the students studying in various schools located in the Roopnagar district of Punjab.

- The study was conducted on adolescents studying in class XII only.

- The study was limited to a sample of 515 twelfth grade students.

- The study was limited to the variable decision making skill of students as dependent variables and self-efficacy, selfregulation, and satisfaction of students with the school as independent variables.

\section{Objectives of the Study}

- The present study was designed to attain the following objectives:

- To study the effect of low, average, and high self-efficacy in the acquisition of decision-making skills.

- To study the effect of low, average, and high self-regulation of students in the acquisition of decision-making skill.

- To study the effect of low, average, and high satisfaction of students with a school in the acquisition of decision-making skill.

- To study the interaction effect between self-efficacy and selfregulation in the acquisition of decision-making skill.

- To study the interaction effect between self-efficacy and satisfaction of students with the school in the acquisition of decision-making skills.

- To study the interaction effect between self-regulation and satisfaction of students in the acquisition of decision-making skills.

- To study the interaction effect among self-efficacy, selfregulation, and satisfaction of students with the school in the acquisition of decision-making skills.

\section{Hypotheses of the Study}

Ho 1: Twelfth graders having high, average, and low self-efficacy will not be significantly different on scores of skill of decision making.

Ho 2: Twelfth graders having high, average and low self-regulation will not be significantly different on scores of the skill of decision making.

Ho 3: Twelfth graders having high, average, and low satisfaction of students with the school will not be significantly different on scores of the skill of decision making.

Ho 4: There will be no significant interaction effect of self-efficacy and self-regulation on scores of the skill of decision making for twelfth graders.

Ho 5: There will be no significant interaction effect of self-efficacy and satisfaction of students with school on scores of skill of decision making for twelfth graders.

Ho 6: There will be no significant interaction effect of self-regulation and satisfaction of students with school on scores of skill of decision making for twelfth graders.

Ho 7: There will be no significant interaction effect of self-efficacy, self-regulation and satisfaction of students with school on scores of skill of decision making for twelfth graders.

\section{Sample}

The sample was comprised of 515 students chosen from representative CBSE affiliated secondary schools of district Roopnagar, Punjab. The survey questionnaire was given to all the 515 students in the above-mentioned schools. The classification of students was done on the basis of self-regulation $(H, A, L)$ selfefficacy $(H, A, L)$ and satisfaction of students with school $(H, A$, $\mathrm{L})$ at the time of analyses.

\section{Tools Used}

Following tools were used for the collection of data.

- Decision making in everyday life scale (Developed and standardized by Mincemoyer, Perkins and Munyua, 2001)

- Self-regulation scale (Developed and validated by Ahuja Malwinder and Suman, 2016).

- Self-efficacy scale (General self-efficacy scale (GSE) by Ralf Schwarzer and Matthias Jerusalem, 1993).

- Satisfaction/Dissatisfaction scale (Student satisfaction scale (FORM A) Developed and standardized by Neal Schmitt and Brain Loher, 1987).

\section{Analysis and Interpretation of Data}

Ex post facto design was employed and $3 \times 3 \times 3$ ANOVA was used to analyze data. Impact of three independent variables (self-efficacy, self-regulation and satisfaction of students with school) was studied on decision-making skill as dependent variable. Significant F-ratios were followed by t-tests.

\section{Descriptive Analysis}

Descriptive statistics techniques like mean, standard deviation were used to describe the nature of data.

The results indicated that scores of skill of decision making for twelfth graders with high satisfaction of students with the school had yielded the most diversity. Therefore $3 \times 3 \times 3$ ANOVA was used to analyses results. The sum of squares, mean sum of squares and F-ratios were computed for scores of skill of decision making. The main effects and interaction effects of various independent variables employing a $3 \times 3 \times 3$ design were 
Study of Decision-making Skill of +2 Students in Relation to their Self-Regulation, Self-Efficacy and Satisfaction with School

Table T. 1: Table of number, means and standard deviation on skill of decision-making in relation to self-efficacy, self-regulation and satisfaction of students with school.

\begin{tabular}{|c|c|c|c|c|}
\hline Variable & Group & Number & Mean & Standard deviation \\
\hline \multirow[t]{3}{*}{ Self-Efficacy (SE) } & High & 186 & 77.17 & 8.21 \\
\hline & Average & 150 & 74.85 & 7.58 \\
\hline & Low & 179 & 73.53 & 7.51 \\
\hline \multirow[t]{3}{*}{ Self-Regulation (SR) } & High & 188 & 77.54 & 7.72 \\
\hline & Average & 153 & 75.20 & 7.46 \\
\hline & Low & 174 & 72.75 & 7.84 \\
\hline \multirow[t]{3}{*}{ Satisfaction of Students with School (SS) } & High & 180 & 78.05 & 7.30 \\
\hline & Average & 155 & 74.65 & 7.55 \\
\hline & Low & 180 & 72.90 & 8.03 \\
\hline
\end{tabular}

Table T.2: Sum of squares, Mean sum of squares and F-ratios for scores of skill of decision Making in relation to Self-Efficacy, Self-Regulation and Satisfaction of Students with the school.

\begin{tabular}{|c|c|c|c|c|}
\hline Source of variation & Sum of squares (s.s) & Degree of freedom & Mean sum of squares & F-Value \\
\hline \multicolumn{5}{|l|}{ Main Effects } \\
\hline Self-Efficacy & 456.71 & 2 & 228.35 & $4.28^{* *}$ \\
\hline Self-regulation & 1104.20 & 2 & 552.10 & $10.34^{* *}$ \\
\hline Satisfaction of students with school & 1203.95 & 2 & 601.98 & $11.27^{* *}$ \\
\hline \multicolumn{5}{|l|}{ Two Order Interaction } \\
\hline$A \times B$ & 269.08 & 4 & 67.27 & 1.26 \\
\hline$A \times C$ & 509.44 & 4 & 127.36 & $2.39 *$ \\
\hline $\mathrm{B} \times \mathrm{C}$ & 280.46 & 4 & 70.12 & 1.31 \\
\hline \multicolumn{5}{|l|}{ Three Order Interaction } \\
\hline $\mathrm{A} \times \mathrm{B} \times \mathrm{C}$ & 853.29 & 8 & 106.66 & $1.99 *$ \\
\hline Error: Within Variable & 26061.91 & 488 & 53.41 & \\
\hline Total & 2946768.0 & 515 & & \\
\hline
\end{tabular}

** Significant at 0.01 level of confidence

* Significant at 0.05 level of confidence

Table T.3: Table of Means, SD's and t-ratios for difference in scores of decision Making for High, average and low levels of Self-Efficacy

\begin{tabular}{llll}
\hline Self-efficacy & High level (A1) & Average level (A2) & Low level (A3) \\
\hline $\mathrm{N}$ & 186 & 150 & 179 \\
$\mathrm{M}$ & 77.17 & 74.85 & 73.53 \\
S.D. (б) & 8.21 & 7.58 & 7.51 \\
High Level (A1) & & $2.66^{* *}$ & $4.42^{* *}$ \\
Average Level (A2) & & & 1.59 \\
Low Level (A3) & & & \\
\hline ***
\end{tabular}

** Significant at 0.01 level of confidence

calculated. The summary of $3 \times 3 \times 3$ design has been presented in the Table T.2.

\section{Main Effects}

\section{Self-Efficacy (A)}

Table T.2 shows that the F-ratio for the difference in the mean scores on the skill of decision making for twelfth graders with high, average, and low self-efficacy was found to be significant at the 0.01 level of confidence. It suggested that there was a significant difference between the mean scores on the skill of decision making for the twelfth grader of high, average, and low self-efficacy groups. The null hypothesis $H_{0} 1$ was rejected at the specified level. It may be inferred that the three groups of twelfth graders were different on the scores of skill of decision making. To ascertain the difference in groups, t-test was applied for various combination groups.
Following sub-hypotheses were tested through these t-ratios:

Ho 1.1: Twelfth graders having high (A1) and average (A2) selfefficacy will not be significantly different on the scores of skill of decision making.

Ho 1.2: Twelfth graders having high ( $A 1)$ and low $(A 3)$ self-regulation will not be significantly different on the scores of skill of decision making.

Ho 1.3: Twelfth graders having average (A2) and low (A3) selfregulation will not be significantly different on the scores of skill of decision making.

Table T.3 shows that, the t-ratio for the difference in the mean scores on skill of decision making for twelfth graders with high (A1) and average (A2) self-efficacy and that for high (A1) and low (A3) self-efficacy were found to be significant at the 0.01 level of confidence. The null hypothesis $H_{0} 1.1$ and $H_{0} 1.2$ were therefore rejected at the specified level. A probe into the means led to infer that; 
- The twelfth graders with high self-efficacy $(M=77.17)$ scored higher on skill of decision making than their counterparts with average self-efficacy ( $M=74.85)$, and

- The twelfth graders with high self-efficacy $(M=77.17)$ achieved higher scores on decision-making than their counterparts with low self-efficacy $(M=73.53)$.

Table T.3 shows that the t-ratio for the difference in the mean scores of skill of decision making for twelfth graders with average (A2) and low (A3) self-efficacy was not found to be significant even at 0.05 level of confidence. The difference, if observed, may be ascribed to chance factors only. The null hypothesis $H_{0}$. 1.3: was not rejected at the specified level. It may be concluded that twelfth graders having average and low self-efficacy achieved equal mean scores on skill of decision making.

\section{Main Effect: Self-Regulation (B)}

Table T.2 shows that the F-ratio for the difference in the mean scores on skill of decision making for twelfth graders with high, average and low self-regulation was found to be significant at the 0.01 level of confidence. It suggested that there was a significant difference between the means of scores on skill of decision making for twelfth grader of high, average and low self-regulation groups. The null hypothesis $\mathrm{HO}_{2}$ was rejected at the specified level. T-test was applied for various combination groups, and corresponding $\mathrm{t}$-ratios have been presented in the following table.

Following sub-hypotheses were tested through these t-ratios:

Ho 2.1: Twelfth graders having high (B1) and average (B2) selfregulation will not be significantly different on the scores of the skill of decision making.

Ho 2.2: Twelfth graders having high (B1) and low (B3) self-regulation will not be significantly different on the scores of the skill of decision making.

Ho 2.3: Twelfth graders having an average (B2) and low (B3) selfregulation will not be significantly different on the scores of skill of decision making.

Table T.4 shows that, the t-ratio for the difference in the mean scores on the skill of decision making for all the three combination groups like; 1 twelfth grader with high (B1) and average (B2) self-regulation and that for 2.the groups of twelfth graders with high (B1) and low (B3) self-regulation and 3. Twelfth graders with average (B2) and low (B3) self-regulation were found to be significant at the 0.01 level of confidence. This indicated that the mean scores of all these three combination groups were different. A probe into the means led to infer that

- The twelfth graders with high self-regulation $(M=77.54)$ achieved higher scores on decision-making than their counterparts with average self-regulation $(M=75.20) H o .2 .1$ rejected

- The twelfth graders with high self-regulation $(M=77.54)$ scored higher on the skill of decision making than their counterparts with low self-regulation $(M=72.75) H o .2 .2$ rejected

- The twelfth graders with average self-regulation $(M=75.20)$ was higher on scores of decision making than their counterparts with low self-regulation $(\mathrm{M}=72.75)$ Ho.2.3 rejected.

\section{Main Effect: Satisfaction of Students with School (C)}

Table T.2 shows that, the F-ratio for the differences in the mean scores of skill of decision making for twelfth graders with high, average and low satisfaction of students with school was found to be significant at the 0.01 level of confidence. It suggested that there was significant difference between the mean scores of skill of decision making for twelfth grader of high, average and low satisfaction of students with school groups. The null hypothesis $\mathrm{H}_{\mathrm{o}} 3$ was rejected at the specified level. It may be inferred that the three groups of twelfth graders were different on the scores of skill of decision making. To ascertain which group of twelfth graders was significantly different from each other, t-test was applied for various combination groups and corresponding t-ratios have been presented in the following table.

Following sub-hypotheses were tested through these t-ratios:

Ho 3.1: Twelfth graders having high (C1) and average (C2) satisfaction of students with school will not be significantly different on the scores of skill of decision making.

Ho 3.2: Twelfth graders having high (C1) and low (C3) satisfaction of students with school will not be significantly different on the scores of skill of decision making.

Table T.4: Table of means, SD's and t-ratios for difference in scores of decision making for high, average and low levels of self-regulation

\begin{tabular}{llll}
\hline Self-regulation & High level (B1) & Average level (B2) & Low level (B3) \\
\hline $\mathrm{N}$ & 188 & 153 & 174 \\
$\mathrm{M}$ & 77.54 & 75.20 & 72.75 \\
$\mathrm{S.D.} \mathrm{( \sigma )}$ & 7.72 & 7.46 & 7.84 \\
High Level (B1) & & $2.82^{* *}$ & $5.85^{* *}$ \\
Average Level (B2) & & & $2.88^{* *}$ \\
Low Level (B3) & & &
\end{tabular}

** Significant at 0.01 level of confidence

Table T.5: Table of Means, SD's and t-ratios for difference in scores of decision making for high, average and low levels of satisfaction of students with school

\begin{tabular}{llll}
\hline Satisfaction of students with school & High level (C1) & Average level (C2) & Low level (C3) \\
\hline $\mathrm{N}$ & 180 & 155 & 180 \\
$\mathrm{M}$ & 78.05 & 74.65 & 72.90 \\
S.D. ( $\sigma)$ & 7.30 & 7.55 & 8.03 \\
High Level (C1) & & $4.18^{* *}$ & $6.37^{* *}$ \\
Average Level (C2) & & $2.05^{*}$ \\
Low Level (C3) & & & \\
\hline
\end{tabular}

** Significant at 0.01 level of confidence

* Significant at 0.05 level of confidence 
Ho 3.3: Twelfth graders having average (C2) and low (C3) satisfaction of students with school will not be significantly different on the scores of skill of decision making.

Table T.5 shows that, the t-ratio for the difference in the mean scores on skill of decision making for two combination groups like; 1 .twelfth graders with high (C1) and average (C2) satisfaction and that for 2.the groups of twelfth graders with high (C1) and low (C3) satisfaction were found to be significant at the 0.01 level of confidence, Whereas Twelfth graders with average (C2) and low (C3) satisfaction were found significantly different at the .005 level of confidence. This indicated that the mean scores of all these three combination groups were different. A probe into the means led to infer that;

- The twelfth graders with high satisfaction of students with school $(M=78.05)$ achieved higher on skill of decision making than their counterparts with average satisfaction of students with school $(\mathrm{M}=74.65), H_{0} 3.1$ was rejected

- The twelfth graders with high satisfaction of students with school $(M=78.05)$ scored higher on skill of decision making than their counterparts with low satisfaction of students with school $(M=72.90) H_{0} 3.2$ was rejected

- The twelfth graders with average satisfaction of students with school $(M=74.65)$ achieved higher on scores of decision making than their counterparts with low satisfaction of students with school $(M=72.90) H_{0} 3.3$ was rejected

\section{Two Order Interaction Effect: Self-Efficacy $\times$ Self- Regulation $(\mathrm{A} \times \mathrm{B})$}

Table T.2 shows that, the F-ratio for the difference in the mean scores on skill of decision making for twelfth graders due to interaction between self-efficacy and self-regulation was not found to be significant even at the 0.05 level of confidence. It suggested that the interaction effect of self-efficacy and self-regulation did not yield significantly different mean scores on skill of decision making for twelfth grader. The null hypothesis $H_{0} 4$ : was not rejected at the specified level. It may be concluded that self-efficacy and selfregulation did not yield different mean scores on skill of decision making for twelfth graders.

\section{Two Order Interaction Effect: Self-Efficacy $x$ Satisfaction of Students With School $(A \times C)$}

Table T.2 shows that, the F-ratio for the difference in the means of scores on skill of decision making for twelfth graders due to the interaction between self-efficacy and satisfaction of students with school was found to be significant at 0.05 level of confidence. It suggested that the interaction effect of self-efficacy and satisfaction of students with school yielded significantly different means on scores of skill of decision making for twelfth graders. The null hypothesis $\mathrm{Ho} 5$ was rejected at the specified level. To ascertain which combination groups of twelfth graders were significantly different from each other, t-test was applied for various combination groups and corresponding t-ratios have been presented in the table T.6. Following sub-hypotheses were tested through these t-ratios:

Ho 5.1: Twelfth graders having high SE, high SS (A1C1) and high $\mathrm{SE}$, average SS (A1C2) will not be significantly different on the scores of skill of decision making.

Ho 5.2: Twelfth graders having high $\mathrm{SE}$, average $\mathrm{SS}$ (A1C2) and high SE, low SS (A1C3) will not be significantly different on the scores of skill of decision making.

Ho 5.3: Twelfth graders having high $\mathrm{SE}$, high SS (A1C1) and high $\mathrm{SE}$, low SS (A1C3) will not be significantly different on the scores of skill of decision making.

Ho 5.4: Twelfth graders having average SE, high SS (A2C1) and average SE, average SS (A2C2) will not be significantly different on the scores of skill of decision making.

Ho 5.5: Twelfth graders having average $\mathrm{SE}$, average $\mathrm{SS}(\mathrm{A} 2 \mathrm{C} 2$ ) and average SE, low SS (A2C3) will not be significantly different on the scores of skill of decision making.

Ho 5.6: Twelfth graders having average SE, high SS (A2C1) and average SE, low SS (A2C3) will not be significantly different on the scores of skill of decision making.

Ho 5.7: Twelfth graders having low SE, high SS (A3C1) and low SE, average SS (A3C2) will not be significantly different on the scores of skill of decision making.

Ho 5.8: Twelfth graders having low SE, high SS (A3C2) and low SE, low SS (A3C3) will not be significantly different on the scores of skill of decision making.

Ho 5.9: Twelfth graders having low $\mathrm{SE}$, high $\mathrm{SS}(\mathrm{A} 3 \mathrm{C} 1)$ and low $\mathrm{SE}$, low SS (A3C3) will not be significantly different on the scores of skill of decision making.

Ho 5.10: Twelfth graders having high SE, high SS (A1C1) and average $\mathrm{SE}$, high SS (A2C1) will not be significantly different on the scores of skill of decision making.

Ho 5.11: Twelfth graders having average SE, high SS (A2C1) and low SE, high SS ( $A 3 C 1$ ) will not be significantly different on the scores of skill of decision making.

Table T.6: Table of Means, SD's and t-ratios for difference in means on skill of decision making for various combination groups due to interaction of self-efficacy and satisfaction of students with school

\begin{tabular}{|c|c|c|c|c|c|c|c|c|c|}
\hline Groups & $A 1 C 1$ & $A 1 C 2$ & A1C3 & $A 2 C 1$ & $A 2 C 2$ & $A 2 C 3$ & $A 3 C 1$ & $A 3 C 2$ & $A 3 C 3$ \\
\hline $\mathrm{N}$ & 80 & 51 & 55 & 47 & 55 & 48 & 53 & 49 & 77 \\
\hline$M$ & 79.05 & 77.61 & 74.02 & 76.83 & 74.27 & 73.58 & 77.62 & 72.00 & 71.68 \\
\hline S.D. (б) & 7.45 & 7.45 & 9.11 & 7.80 & 6.92 & 7.84 & 6.51 & 7.37 & 7.22 \\
\hline $\mathrm{A} 1 \mathrm{C} 1$ & & 1.08 & $3.52^{* * *}$ & 1.59 & $3.77^{* *}$ & $3.94^{* * *}$ & 1.14 & $5.24^{* *}$ & $6.29 * *$ \\
\hline $\mathrm{A} 1 \mathrm{C} 2$ & & & $2.21^{* *}$ & .51 & $2.39^{* *}$ & $2.62^{* *}$ & .01 & $3.83^{* *}$ & $4.49^{* * *}$ \\
\hline $\mathrm{A} 1 \mathrm{C} 3$ & & & & 1.59 & .17 & .26 & $2.36^{*}$ & 1.23 & 1.65 \\
\hline $\mathrm{A} 2 \mathrm{C} 1$ & & & & & 1.75 & $2.02^{*}$ & .55 & $3.12^{* *}$ & $3.74 * *$ \\
\hline $\mathrm{A} 2 \mathrm{C} 2$ & & & & & & .47 & $2.59^{* *}$ & 1.62 & $2.07^{*}$ \\
\hline $\mathrm{A} 2 \mathrm{C} 3$ & & & & & & & $2.83^{* *}$ & 1.03 & 1.39 \\
\hline $\mathrm{A} 3 \mathrm{C} 1$ & & & & & & & & $4.09 * *$ & $4.80^{* * *}$ \\
\hline $\mathrm{A} 3 \mathrm{C} 2$ & & & & & & & & & .24 \\
\hline $\mathrm{A} 3 \mathrm{C} 3$ & & & & & & & & & \\
\hline
\end{tabular}

** Significant at 0.01 level of confidence

* Significant at 0.05 level of confidence 
Study of Decision-making Skill of +2 Students in Relation to their Self-Regulation, Self-Efficacy and Satisfaction with School

Ho 5.12: Twelfth graders having high $\mathrm{SE}$, high $\mathrm{SS}(\mathrm{A} 1 \mathrm{C} 1)$ and low SE, high SS (A3C1) will not be significantly different on the scores of skill of decision making.

Ho 5.13: Twelfth graders having high SE, average SS (A1C2) and average $\mathrm{SE}$, average $\mathrm{SS}(\mathrm{A} 2 \mathrm{C} 2$ ) will not be significantly different on the scores of skill of decision making.

Ho 5.14: Twelfth graders having average SE, average SS (A2C2) and low $\mathrm{SE}$, average SS (A3C2) will not be significantly different on the scores of skill of decision making.

Ho 5.15: Twelfth graders having high SE, average SS (A1C2) and low $\mathrm{SE}$, average $\mathrm{SS}(\mathrm{A} 3 \mathrm{C} 2)$ will not be significantly different on the scores of skill of decision making.

Ho 5.16: Twelfth graders having high SE, low SS (A1C3) and average $\mathrm{SE}$, low SS (A2C3) will not be significantly different on the scores of skill of decision making.

Ho 5.17: Twelfth graders having average SE, low SS (A2C3) and low SE, low SS (A3C3) will not be significantly different on the scores of skill of decision making.

Ho 5.18: Twelfth graders having high SE, low SS (A1C3) and low SE, low SS (A3C3) will not be significantly different on the scores of skill of decision making.

As shown in table T.6, the t-ratios for the difference in the means of scores on skill of decision making for twelfth graders were found to be significant at the 0.01 level of confidence for the following combination group viz. (A1C2-A1C3, A1C1-A1C3, A3C1-A3C2, $A 3 C 1-$ $A 3 C 3, A 1 C 2-A 2 C 2$ and $A 1 C 2-A 3 C 2)$. This indicated that all these six combination groups were different in their mean scores beyond any chance factors. Therefore the corresponding hypotheses Ho5.2, Ho 5.3, Ho 5.7, Ho 5.9, Ho 5.13 and Ho 5.15 stand rejected at the specified level. An examination of their means led to following conclusions:

- High SE and Average SS (A1C2) achieved higher mean scores on skill of decision making as compared to their counterparts high SE and low SS (A1C3). Ho 5.2 was rejected.

- High SE and high SS (A1C1) scored higher means on skill of decision making as compared to their counterparts high SE and low SS (A1C3). Ho 5.3 rejected.

- Low SE and high SS (A3C1) achieved higher mean scores on skill of decision making as compared to their counterparts low SE and Average SS (A3C2). Ho 5.7 rejected.

- Low SE and high SS (A3C1) scored higher mean scores on skill of decision making as compared to their counterparts low SE and low SS (A3C3). Ho 5.9 rejected.

- High SE and Average SS (A1C2) scored higher mean scores on skill of decision making as compared to their counterparts Average SE and Average SS (A2C2). Ho 5.13 rejected.

- High SE and Average SS (A1C2) achieved higher mean scores on skill of decision making as compared to their counterparts low SE and Average SS (A3C2). Ho 5.15 rejected.

- Similarly in table T.6 the t-ratios for the differences in the means of scores on skill of decision making for the group $\mathrm{A} 2 \mathrm{C} 1-\mathrm{A} 2 \mathrm{C} 3$ were found to be significant at the 0.05 level of confidence. This indicated that these groups were different in their mean scores beyond any chance factors. The means of the two groups in the above mentioned combination groups led to the following conclusion:

- Average SE and low SS (A2C1) were higher on mean scores for skill of decision making as compared to their counterparts Average SE and low SS (A2C3). Ho 5.6 rejected.

- However as shown in table T.6, the t-ratios for the difference in means on scores of skill of decision making for twelfth graders in the following combination groups $\mathrm{A} 1 \mathrm{C} 1-\mathrm{A} 1 \mathrm{C} 2, \mathrm{~A} 2 \mathrm{C} 1-\mathrm{A} 2 \mathrm{C} 2$, $\mathrm{A} 2 \mathrm{C} 2-\mathrm{A} 2 \mathrm{C} 3, \mathrm{~A} 3 \mathrm{C} 2-\mathrm{A} 3 \mathrm{C} 3, \mathrm{~A} 1 \mathrm{C} 1-\mathrm{A} 2 \mathrm{C} 1, \mathrm{~A} 2 \mathrm{C1}-\mathrm{A} 3 \mathrm{C} 1, \mathrm{~A} 1 \mathrm{C} 1-\mathrm{A} 3 \mathrm{C} 1$, $A 2 C 2-A 3 C 2, A 1 C 3-A 2 C 3, A 2 C 3-A 3 C 3$ and $A 1 C 3-A 3 C 3$ were not found to be significant even at the 0.05 level of confidence. The observed difference in means of these groups may be ascribed to chance factor only. Hence the corresponding null Ho 5.1, Ho 5.4, Ho 5.5, Ho 5.8, Ho 5.10, Ho 5.11, Ho 5.12, Ho 5.14, Ho 5.16, Ho 5.17 and $H o 5.18$ were not rejected at the specified level. This led to the following conclusions.

- High SE, high SS (A1C1) and high SE, average SS (A1C2) of twelfth graders achieved equal mean scores on skill of decision Making. Ho 5.1 was not rejected.

- Mean scores of Average SE, high SS (A2C1) and Average SE, average $\mathrm{SS}$ ( $\mathrm{A} 2 \mathrm{C} 2$ ) of twelfth graders on skill of decision making were not different. Ho 5.4 was not rejected.

- Average SE, average SS (A2C2) and Average SE, low SS (A2C3) of twelfth graders achieved equal mean scores on skill of decision Making. Ho 5.5 was not rejected.

- Low SE, average SS (A3C2) and low SE, low SS (A3C3) of twelfth graders achieved equal mean scores on skill of decision Making. Ho 5.8 was not rejected.

- Mean scores of high SE, high SS (A1C1) and Average SE, high SS (A2C1) of twelfth graders on skill of decision making were not different. Ho 5.10 was not rejected.

- Mean scores of Average SE, high SS (A2C1) and low SE, high SS (A3C1) of twelfth graders on skill of decision making were not different. Ho 5.11 was not rejected.

- Mean scores of high SE, high SS (A1C1) and low SE, high SS $(A 3 C 1)$ of twelfth graders on skill of decision making were not different. Ho 5.12 was not rejected.

- Mean scores of Average SE, average SS (A2C2) and low SE, average $\mathrm{SS}(\mathrm{A} 3 \mathrm{C} 2$ ) of twelfth graders on skill of decision making were not different. Ho 5.14 was not rejected.

- Mean scores of high SE, low SS (A1C3) and Average SE, low SS (A2C3) of twelfth graders on skill of decision making were not different. Ho 5.16 was not rejected.

- Mean scores of Average SE, low SS (A2C3) and low SE, low SS (A3C3) of twelfth graders on skill of decision making were not different. Ho 5.17 was not rejected.

- Mean scores of high SE, low SS (A1C3) and low SE, low SS (A3C3) of twelfth graders on skill of decision making were not different. Ho 5.18 was not rejected.

Only these primary combination groups were considered relevant for the present study therefore t-ratio for only these groups were interpreted.

\section{Two Order Interaction Effect: Self-Regulation $\times$ Satisfaction of Students with SchooL $(B \times C)$}

Table T.2 shows that, the F-ratio for the difference in the mean scores on skill of decision making for twelfth graders due to interaction between self-regulation and satisfaction of students with school was not found to be significant even at the 0.05 level of confidence. It suggested that the interaction effect of self-regulation and satisfaction of students with school did not yield significantly different mean scores on skill of decision making for twelfth grader. The difference if observed may be ascribed to chance factor only. The null hypothesis $H_{0} 6$ was not rejected at the specified level. It may be concluded that self-regulation and satisfaction of students with school did not yield different mean scores on skill of decision making for twelfth graders. 


\section{Three Order Interaction Effect: Self-Efficacy $\times$ Self- Regulation $\times$ Satisfaction of Students with School $(\mathrm{A} \times \mathrm{B} \times \mathrm{C})$}

Table T.2 shows that, the F-ratio for the difference in the means of scores on skill of decision making for twelfth graders due to the interaction between self-efficacy, self-regulation and satisfaction of students with school was found to be significant at 0.05 level of confidence. It suggested that the interaction effect of self-efficacy, self-regulation and satisfaction of students with school yielded significantly different means on scores of skill of decision making for twelfth graders. The null hypothesis $\mathrm{Ho}$ 7: which stated that there will be no significant interaction effect of self-efficacy, selfregulation and satisfaction of students with school on the scores of skill of decision making for twelfth graders was rejected at the specified level. It may be inferred that the various combination groups of twelfth graders were different beyond any chance factors on their scores on skill of decision making. To ascertain, which group of twelfth graders was significantly different from each other, t-test was applied for various combination groups and corresponding t-ratios have been presented in the table T.7.

Following sub-hypotheses were tested through these t-ratios:

Ho 7.1: Twelfth graders having high SE, high SR, high SS (A1B1C1) and high SE, high SR, average SS (A1B1C2) will not be significantly different on the scores of skill of decision making.

Ho 7.2: Twelfth graders having high SE, high SR, high SS (A1B1C1) and high SE, high SR, low SS (A1B1C3) will not be significantly different on the scores of skill of decision making.

Ho 7.3: Twelfth graders having high $S E$, high $S R$, average SS (A1B1C2) and high SE, high SR, low SS (A1B1C3) will not be significantly different on the scores of skill of decision making.

Ho 7.4: Twelfth graders having high SE, average SR, high SS (A1B2C1) and high SE, average SR, average SS (A1B2C2) will not be significantly different on the scores of skill of decision making.

Ho 7.5: Twelfth graders having high SE, average SR, high SS (A1B2C1) and high SE, average SR, low SS (A1B2C3) will not be significantly different on the scores of skill of decision making.

Ho 7.6: Twelfth graders having high $\mathrm{SE}$, average SR, average SS (A1B2C2) and high SE, average SR, low SS (A1B2C3) will not be significantly different on the scores of skill of decision Making.

Ho 7.7: Twelfth graders having high SE, low SR, high SS (A1B3C1) and high SE, low SR, average SS (A1B3C2) will not be significantly different on the scores of skill of decision making.

Ho 7.8: Twelfth graders having high $\mathrm{SE}$, low SR, high SS (A1B3C1) and high SE, low SR, low SS (A1B3C3) will not be significantly different on the scores of skill of decision making.

Ho 7.9: Twelfth graders having high SE, low SR, average SS (A1B3C2) and high SE, low SR, low SS (A1B3C3) will not be significantly different on the scores of skill of decision making.

Ho 7.10: Twelfth graders having average SE, high SR, high SS (A2B1C1) and average SE, high SR, average SS (A2B1C2) will not be significantly different on the scores of skill of decision making.

Ho 7.11: Twelfth graders having average SE, high SR, high SS (A2B1C1) and average SE, high SR, low SS (A2B1C3) will not be significantly different on the scores of skill of decision making.

Ho 7.12: Twelfth graders having average $S E$, high $S R$, average $S S$ (A2B1C2) and average SE, high SR, low SS (A2B1C3) will not be significantly different on the scores of skill of decision making.

Ho 7.13: Twelfth graders having average $S E$, average $S R$, high SS (A2B2C1) and average SE, average SR, average SS (A2B2C2) will not be significantly different on the scores of skill of decision making.

Ho 7.14: Twelfth graders having average SE, average SR, high SS (A2B2C1) and average SE, average SR, low SS (A2B2C3) will not be significantly different on the scores of skill of decision making.

Ho 7.15: Twelfth graders having average $S E$, average $S R$, average SS (A2B2C2) and average SE, average SR, low SS (A2B2C3) will not be significantly different on the scores of skill of decision making.

Ho 7.16: Twelfth graders having average SE, low SR, high SS (A2B3C1) and average $\mathrm{SE}$, low $\mathrm{SR}$, average $\mathrm{SS}$ (A2B3C2) will not be significantly different on the scores of skill of decision making.

Ho 7.17: Twelfth graders having average SE, low SR, high SS (A2B3C1) and average SE, low SR, low SS (A2B3C3) will not be significantly different on the scores of skill of decision making.

Ho7.18: Twelfth graders having average $S E$, low $S R$, average SS (A2B3C2) and average SE, low SR, low SS (A2B3C3) will not be significantly different on the scores of skill of decision making.

Ho 7.19: Twelfth graders having low SE, high SR, high SS (A3B1C1) and low SE, high SR, average SS (A3B1C2) will not be significantly different on the scores of skill of decision making.

Ho 7.20: Twelfth graders having low SE, high SR, high SS (A3B1C1) and low SE, high SR low SS (A3B1C3) will not be significantly different on the scores of skill of decision making.

Ho 7.21: Twelfth graders having low $S E$, high $S R$, average $S S$ (A3B1C2) and low SE, high SR, low SS (A3B1C3) will not be significantly different on the scores of skill of decision making.

Ho 7.22: Twelfth graders having low SE, average SR, high SS (A3B2C1) and low SE, average SR, average SS (A3B2C2) will not be significantly different on the scores of skill of decision making.

Ho 7.23: Twelfth graders having low $S E$, average $S R$, high SS (A3B2C1) and low SE, average SR, low SS (A3B2C3) will not be significantly different on the scores of skill of decision making.

Ho 7.24: Twelfth graders having low $S E$, average $S R$, average $S S$ (A3B2C2) and low SE, average SR, low SS (A3B2C3) will not be significantly different on the scores of skill of decision making.

Ho 7.25: Twelfth graders having low SE, low SR, high SS (A3B3C1) and low SE, low SR, average SS (A3B3C2) will not be significantly different on the scores of skill of decision making.

Ho 7.26: Twelfth graders having low SE, low SR, high SS (A3B3C1) and low SE, low SR, low SS (A3B3C3) will not be significantly different on the scores of skill of decision making.

Ho 7.27: Twelfth graders having low SE, low SR, average SS (A3B3C2) and low SE, low SR, low SS (A3B3C3) will not be significantly different on the scores of skill of decision making. 
Study of Decision-making Skill of +2 Students in Relation to their Self-Regulation, Self-Efficacy and Satisfaction with School

As shown in table T.7, the t-ratios for the difference in the means of scores on skill of decision making for twelfth graders were found to be significant at the 0.01 level of confidence for the following combination group viz. A1B1C1-A1B1C3, A1B1C2-A1B1C3, A1B2C1A1B2C3, A2B1C1-A2B1C3, A3B1C1-A3B1C2, and A3B3C1-A3B3C3. This indicated that all these groups were different in their mean scores beyond any chance factors. Therefore the corresponding Ho 7.2, Ho 7.3, Ho 7.5, Ho 7.11, Ho 7.19, Ho 7.26, were rejected at the specified levels. An examination of means of the two groups in each of the above mentioned combination groups led to the following conclusions:

\section{With high Self Efficacy}

- High SR, high SS (A1B1C1) achieved higher mean scores on skill of decision making as compared to their counterparts of high SR and low SS (A1B1C3). Ho 7.2 rejected.

- High SR, average SS (A1B1C2) scored higher means on skill of decision making as compared to their counterparts of high SR and low SS (A1B1C3). Ho 7.3 rejected.

\section{With Average Self Efficacy'}

- Average SR, high SS (A1B2C1) was higher on mean scores for skill of decision making as compared to their counterparts of Average SR and low SS (A1B2C3). Ho 7.5 rejected.

- High SR, high SS (A2B1C1) was higher on mean scores for skill of decision making as compared to their counterparts of high SR and low SS (A2B1C3). Ho 7.11 rejected.

\section{With low Self Efficacy}

- High SR, high SS (A3B1C1) was higher on mean scores for skill of decision making as compared to their counterparts low $\mathrm{SE}$, high SR, average SS (A3B1C2). Ho 7.19 rejected.

- Low SR, high SS (A3B3C1) was higher on mean scores for skill of decision making as compared to their counterparts low SR, low SS (A3B3C3). Ho 7.26 rejected.

Similarly in table T.7, the t-ratios for the difference in the means of scores on skill of decision making for the group A2B1C1-A2B1C2, $A 3 B 1 C 1-A 3 B 1 C 3$ and $A 3 B 3 C 1-A 3 B 3 C 2$ were found to be significant at the 0.05 level of confidence. This indicated that all these groups were different in their mean scores beyond any chance factors. Therefore the corresponding Ho 7.10, Ho 7.20 and Ho 7.25 were rejected at the specified levels. An examination of means of the two groups in each of the above mentioned combination groups led to the following conclusions:

- Average SE, high SR, high SS (A2B1C1) achieved higher mean scores on skill of decision making as compared to their counterparts Average SE, high SR, average SS (A2B1C2). Therefore, Ho 7.10 was rejected.

- Low SE, high SR, high SS (A3B1C1) scored higher means scores on skill of decision making as compared to their counterparts low SE, high SR and low SS (A3B1C3). Therefore, Ho 7.20 was rejected.

- Low SE, low SR, high SS (A3B3C1) was higher on mean scores on skill of decision making as compared to their counterparts low SE, low SR, average SS (A3B3C2). Therefore, Ho 7.25 was rejected

Table T.7: Table of t-ratios for difference in means on skill of decision making for various combination groups due to interaction of self-efficacy, self-regulation and satisfaction of students with school.

\begin{tabular}{|c|c|c|c|c|c|c|c|c|c|c|c|c|c|c|c|c|c|c|c|c|c|c|c|c|c|c|c|}
\hline & $\begin{array}{ll}\mathrm{A} 1 \mathrm{B1} 1 \\
\mathrm{Cl}\end{array}$ & $\begin{array}{l}\mathrm{AlBI}_{\mathrm{C}} \\
\mathrm{C}^{2}\end{array}$ & $\mathrm{AlBI}_{\mathrm{C}}$ & $\begin{array}{l}\mathrm{AlB2}^{2} \\
\mathrm{Cl}\end{array}$ & $\begin{array}{l}\mathrm{AlB2}^{2} \\
\mathrm{Cl}^{2}\end{array}$ & $\begin{array}{l}\mathrm{AlB2}_{\mathrm{C}} \\
\mathrm{Cl}\end{array}$ & $\begin{array}{l}\text { A1B3 } \\
\mathrm{Cl}\end{array}$ & $\begin{array}{l}\text { A1BI } \\
C_{2}\end{array}$ & 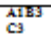 & $\begin{array}{l}\mathrm{A}_{\mathrm{Cl}}^{281} \\
\end{array}$ & $\begin{array}{l}\mathrm{A2B1}^{2 \mathrm{~B}} \\
\mathrm{C} 2\end{array}$ & $\begin{array}{l}\mathrm{AlB1}^{28 \mathrm{~B}} \\
\mathrm{Cl}\end{array}$ & 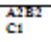 & $\begin{array}{l}A^{2} \mathrm{BE} \\
\mathrm{C}^{2}\end{array}$ & $\begin{array}{l}\mathrm{A}^{2282} \\
\mathrm{C}^{3}\end{array}$ & $\begin{array}{l}\mathrm{AlBO}^{283} \\
\mathrm{Cl}\end{array}$ & $\begin{array}{l}2283 \\
{ }_{2}\end{array}$ & $\mathrm{Cl}^{\mathrm{A}^{283}}$ & $\begin{array}{ll}2381 \\
\mathrm{Cl}^{2}\end{array}$ & $\begin{array}{l}\text { A3E1 } \\
\mathrm{C2}^{2}\end{array}$ & $\begin{array}{c}\mathrm{AJB1}_{\mathrm{C}} \\
\mathrm{Cl}\end{array}$ & $\begin{array}{l}\text { ASB2 } \\
\mathrm{Cl}\end{array}$ & $\begin{array}{l}\text { ASB22 } \\
\mathrm{C}^{2}\end{array}$ & \begin{tabular}{l|} 
ASB2 \\
$C_{3}$
\end{tabular} & $\begin{array}{l}38 \mathrm{BS} \\
\mathrm{Cl}\end{array}$ & $\begin{array}{l}{ }_{\text {ASB3 }} \\
\mathrm{C2}^{2}\end{array}$ & $\begin{array}{l}\text { ASBES } \\
\mathrm{CS}^{3}\end{array}$ \\
\hline $\mathrm{T}$ & 49 & 21 & 17 & 26 & 17 & 14 & 11 & 19 & 24 & 26 & 12 & 14 & 3 & 20 & 14 & 13 & 23 & 20 & 15 & 22 & 15 & 20 & 13 & 21 & 18 & 14 & 38 \\
\hline $\mathrm{X}$ & 79.18 & 30.2 & 79.35 & 79.19 & 7.47 & 72.21 & 75.79 & 73.62 & 75.34 & 79.69 & 74.25 & 73.50 & 73.37 & 75.25 & 72.07 & 7292 & 79.44 & 74.70 & 31.39 & 73.59 & 76.33 & 76.30 & 71.77 & 78.10 & 75.44 & 60.71 & 68.13 \\
\hline 50. (a) & 725 & 6.35 & 10.63 & 6.42 & 7.69 & 7.35 & 295 & 7.44 & 8.76 & 6.72 & 759 & 3.39 & 10.53 & 795 & 6.30 & 538 & 5.71 & 8.59 & 4.59 & 6.32 & 6.33 & 6.26 & 2.00 & 5.00 & 7.11 & 7.16 & 6.53 \\
\hline AIBIC1 & & 203 & $2.7 \%$ & 36 & 1.11 & $3.34^{\circ}$ & 1.54 & 2.690 & $2.15^{\circ}$ & 97 & $233^{\circ}$ & $2,72^{\circ}$ & 193 & $2.26^{\circ}$ & $3.35^{\circ}$ & $3.13^{\circ}$ & $3.65^{\circ}$ & $2.46^{\circ}$ & .76 & $3.41^{\circ}$ & 1.49 & 1.60 & $3.31^{2}$ & 3.590 & $2.16^{\circ}$ & $4.54^{\circ}$ & $7.41^{m}$ \\
\hline AIBIC2 & & & $2.46^{\circ}$ & 53 & 1.19 & 3,300 & 1.54 & $2.74^{\circ}$ & 2.01 & 26 & 2.400 & $2.65^{\circ}$ & 195 & 2.190 & 3.70 & $3,32^{\circ}$ & $3.71^{\circ}$ & $2.33^{*}$ & 59 & $3.41^{m}$ & 1.59 & 1.72 & $3.19^{2}$ & $3.35^{\circ}$ & 2.190 & $4.53^{\circ}$ & $6.62=$ \\
\hline AlBIC & & & & $2.25^{\circ}$ & 1.29 & 33 & 3 & .03 & $\pi 2$ & $2.40^{\circ}$ & .25 & .04 & .12 & .62 & 39 & .19 & .03 & .49 & $2.69^{\circ}$ & 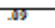 & 1.16 & 1.22 & .43 & 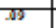 & .69 & 1.00 & $2.1 \%$ \\
\hline AIBIC1 & & & & & $\pi$ & $3.03=$ & 1.27 & $2.43^{\circ}$ & 1.69 & $\sqrt{2.27}$ & $2.03^{\circ}$ & 2.400 & 1.75 & 1.56 & 3,37 & $295^{\circ}$ & $3.29=$ & $2.03^{*}$ & 1.13 & $3.03^{\circ}$ & 1.17 & 1.27 & 257 & 3,379 & 1.32 & $4.23^{\circ}$ & $6.49 \mathrm{~W}$ \\
\hline A1B2C: & & & & & & 1.35 & 52 & 1.35 & 73 & 1.00 & 1.12 & 1.39 & T & 36 & $2.11^{\circ}$ & 1.77 & 191 & 1.03 & 1.69 & 1.73 & .26 & .29 & 1.57 & 194 & 31 & $2.35 \%$ & $4.45 \mathrm{~m}$ \\
\hline A1B2CS & & & & & & & 99 & .43 & 1.17 & $3.17 \%$ & .67 & 42 & .42 & 1.10 & .05 & .26 & 55 & 36 & $3.55^{\circ}$ & 58 & 1.78 & 1.39 & .14 & .65 & 1.22 & .35 & 1.31 \\
\hline AIBSCI & & & & & & & & 0.58 & .056 & 1.42 & .40 & .61 & 39 & .15 & 1.12 & 36 & 36 & 30 & 193 & 75 & 36 & 37 & 1.02 & 34 & $\pi$ & 1.76 & $2.35 \mathrm{~m}$ \\
\hline A1BSC2 & & & & & & & & & 20.93 & $2.5 \%$ & .21 & .04 & $\pi$ & 30 & 35 & .26 & .03 & 3 & 3.43* & $\sqrt{-1.1}$ & -1.40 & -1.46 & 0.43 & $\sqrt{1.17}$ & $\sqrt{5.55}$ & 1.22 & $2.12^{\circ}$ \\
\hline AIBSCI & & & & & & & & & & 1.39 & -44 & $-\pi$ & .A4 & 12 & 125 & 90 & 91 & 32 & 2380 & 50 & 32 & 34 & 1.24 & 92 & .54 & $2+12$ & 3.000 \\
\hline ALEICI & & & & & & & & & & & $2+33^{2}$ & $2=$ & 131 & $2.03^{\circ}$ & उ.45 & उ.0\% & उ.Aश & $2.21^{\circ}$ & 34 & $3.22^{\circ}$ & 1.38 & 1.49 & उ.गण & 3.32 & $2.01 \%$ & $435^{\circ}$ & 0.010 \\
\hline RLEICI & & & & & & & & & & & & .24 & JP & $3=$ & 30 & AS & 36 & 12 & 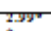 & 21 & M & 1.03 & -14 & 32 & -4A & 1.51 & 2.014 \\
\hline XIETLCS & & & & & & & & & & & & & .09 & .02 & $x$ & 31 & .03 & $A 1$ & 319 & - 94 & 1254 & 132 & 32 & .03 & -11 & 125 & 234 \\
\hline XIEXCI & & & & & & & & & & & & & & 38 & $r$ & -21 & 12 & 22 & 2359 & 20 & 58 & 91 & (4) & $n$ & $4=$ & 1111 & 194 \\
\hline XIEXCL & & & & & & & & & & & & & & & 1.22 & 90 & 5 & 21 & $200 \%$ & $\pi$ & .08 & $S 0$ & 1.1 & 53 & .05 & $2.05^{\circ}$ & $3.34=$ \\
\hline RLERCI & & & & & & & & & & & & & & & & 30 & .05 & श) & 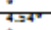 & $-\pi$ & 2.02 & $2 \times 10$ & -10 & 81 & 1.35 & 92 & 130 \\
\hline LEBSCI & & & & & & & & & & & & & & & & & & $8=$ & $4+50$ & 31 & 1.07 & $1 . / 8$ & 35 & 36 & 1.02 & 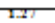 & $53^{2}$ \\
\hline मसBJCL & & & & & & & & & & & & & & & & & & .98 & क्सश & ST & 1.14 & 134 & .95 & 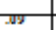 & 1.00 & 1.19 & उ.गण \\
\hline XIESTLS & & & & & & & & & & & & & & & & & & & $2 \pi 1^{2}$ & 45 & 34 & 35 & T4 & 3 & I & $.1 . / 8$ & $3.10 \mathrm{~m}$ \\
\hline ग्रुसापा & & & & & & & & & & & & & & & & & & & & & & कारण & & & & (4) & 57 \\
\hline 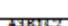 & & & & & & & & & & & & & & & & & & & & 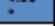 & $=$ & 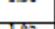 & 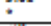 & 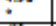 & $\div$ & 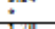 & . \\
\hline 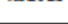 & & & & & & & & & & & & & & & & & & & & & $1=50$ & 1.00 & $\pi 0$ & & & & \\
\hline XSEICI & & & & & & & & & & & & & & & & & & & & & & .02 & $1 . / 8$ & $1 \pi$ & 3 & 2.307 & $4.43^{m}$ \\
\hline XSBELCI & & & & & & & & & & & & & & & & & & & & & & & 1.82 & 1.39 & .09 & 3.080 & 4.007 \\
\hline X्रJEसCL & & & & & & & & & & & & & & & & & & & & & & & & $\pi$ & 121 & .00 & 1.30 \\
\hline DSBRCS & & & & & & & & & & & & & & & & & & & & & & & & & T2 & 1.94 & 3/25 \\
\hline म्बहजटा & & & & & & & & & & & & & & & & & & & & & & & & & & & \\
\hline DS & & & & & & & & & & & & & & & & & & & & & & & & & & & $\pi$ \\
\hline $\mathrm{EJC3}$ & & & & & & & & & & & & & & & & & & & & & & & & & & & \\
\hline
\end{tabular}

** Significant at 0.01 level of confidence

* Significant at 0.05 level of confidence 
Study of Decision-making Skill of +2 Students in Relation to their Self-Regulation, Self-Efficacy and Satisfaction with School

As shown in Table T.7, the t-ratios for the difference in means on scores of skill of decision making for twelfth graders in the following combination groups A1B1C1-A1B1C2, A1B2C1-A1B2C2, A1B2C2-A1B2C3, A1B3C1-A1B3C2, A1B3C1-A1B3C3, A1B3C2-A1B3C3, $\mathrm{A} 2 \mathrm{~B} 1 \mathrm{C} 2-\mathrm{A} 2 \mathrm{~B} 1 \mathrm{C} 3, \mathrm{~A} 2 \mathrm{~B} 2 \mathrm{C} 1-\mathrm{A} 2 \mathrm{~B} 2 \mathrm{C} 2, \mathrm{~A} 2 \mathrm{~B} 2 \mathrm{C} 1-\mathrm{A} 2 \mathrm{~B} 2 \mathrm{C} 3, \mathrm{~A} 2 \mathrm{~B} 2 \mathrm{C} 2-$ $A 2 B 2 C 3, A 2 B 3 C 1-A 2 B 3 C 2, A 2 B 3 C 1-A 2 B 3 C 3, A 2 B 3 C 2-A 2 B 3 C 3$, $A 3 B 1 C 2-A 3 B 1 C 3, A 3 B 2 C 1-A 3 B 2 C 2, A 3 B 2 C 1-A 3 B 2 C 3, A 3 B 2 C 2-$ $A 3 B 2 C 3$, and $A 3 B 3 C 2-A 3 B 3 C 3$ were not found to be significant even at the 0.05 level of confidence. The observed difference in means of these groups may be ascribed to chance factor only. Hence the corresponding null hypotheses Ho 7.1, Ho 7.4, Ho 7.6, Ho 7.7, Ho 7.8, Ho 7.9, Ho 7.12, Ho 7.13, Ho 7.14, Ho 7.15, Ho 7.16, Ho 7.17, Ho 7.18, Ho 7.21, Ho 7.22, Ho 7.23, Ho 7.24, and Ho 7.27, were not rejected at the specified level. An examination of means on skill of decision making of each of these combination groups led to the following conclusions.

- High SE, high SR, high SS (A1B1C1) and high SE, high SR, average SS (A1B1C2) of twelfth graders achieved equal mean scores on skill of hecision making. Therefore, Ho 7.1 was not rejected.

- High SE, average SR, high SS (A1B2C1) and high SE, average SR, average SS (A1B2C2) of twelfth graders achieved equal mean scores on skill of decision making. Therefore, Ho 7.4 was not rejected.

- High SE, average SR, average SS (A1B2C2) and high SE, average SR, low SS (A1B2C3) of twelfth graders achieved equal mean scores on skill of decision making. Therefore, Ho 7.6 was not rejected.

- High SE, low SR, high SS (A1B3C1) and high SE, low SR, average SS (A1B3C2) of twelfth graders achieved equal mean scores on skill of decision making. Therefore, Ho 7.7 was not rejected.

- High SE, low SR, high SS (A1B3C1) and high SE, low SR, low SS (A1B3C3) of twelfth graders achieved equal mean scores on skill of decision making. Therefore, Ho 7.8 was not rejected.

- High SE, low SR, average SS (A1B3C2) and high SE, low SR, low SS (A1B3C3) of twelfth graders achieved equal mean scores on skill of decision making. Therefore, Ho 7.9 was not rejected.

- Average SE, high SR, average SS (A2B1C2) and average SE, high SR, low SS (A2B1C3) of twelfth graders achieved equal mean scores on skill of decision making. Therefore, Ho 7.12 was not rejected.

- Average SE, average SR, high SS (A2B2C1) and average SE, average SR, average SS (A2B2C2) of twelfth graders achieved equal mean scores on skill of decision making. Therefore, Ho 7.13 was not rejected.

- Average SE, average SR, high SS (A2B2C1) and average SE, average SR, low SS (A2B2C3) of twelfth graders achieved equal mean scores on skill of decision making. Therefore, $\mathrm{Ho} 7.14$ was not rejected.

- Average SE, average SR, average SS (A2B2C2) and average SE, average SR, low SS (A2B2C3) of twelfth graders achieved equal mean scores on skill of decision making. Therefore, Ho 7.15 was not rejected.

- Average SE, low SR, high SS (A2B3C1) and average SE, low SR, average SS (A2B3C2) of twelfth graders achieved equal mean scores on skill of decision making. Therefore, Ho 7.16 was not rejected.

- Average SE, low SR, high SS (A2B3C1) and average SE, low SR, low SS (A2B3C3) of twelfth graders achieved equal mean scores on skill of decision making. Therefore, Ho 7.17 was not rejected.

- Average SE, low SR, average SS (A2B3C2) and average SE, low SR, low SS (A2B3C3) of twelfth graders achieved equal mean scores on skill of decision making. Therefore, $\mathrm{Ho} 7.18$ was not rejected.
- Low SE, high SR, average SS (A3B1C2) and low SE, high SR, low SS (A3B1C3) of twelfth graders achieved equal mean scores on skill of decision making. Therefore, Ho 7.21 was not rejected.

- Low SE, average SR, high SS (A3B2C1) and low SE, average SR, average SS (A3B2C2) of twelfth graders achieved equal mean scores on skill of decision making. Therefore, Ho 7.22 was not rejected.

- Low SE, average SR, high SS (A3B2C1) and low SE, average SR, low SS (A3B2C3) of twelfth graders achieved equal mean scores on skill of decision making. Therefore, Ho 7.23 was not rejected.

- Low SE, average SR, average SS (A3B2C2) and low SE, average SR, low SS (A3B2C3) of twelfth graders achieved equal mean scores on skill of decision making. Therefore, Ho 7.24 was not rejected. - Low SE, low SR, average SS (A3B3C2) and low SE, low SR, low SS (A3B3C3) of twelfth graders achieved equal mean scores on skill of decision making. Therefore, Ho 7.27 was not rejected.

Only these primary combination groups were considered relevant for the present study therefore t-ratio for only these groups were interpreted.

\section{Major Findings}

In the light of the interpretation of the results of the present study, the following conclusions were drawn:

\section{Conclusion Based on $3 \times 3 \times 3$ Anova on Scores of Skill of decision making in Relation to Self-Efficacy, Self- Regulation and Satisfaction of Students with School.}

- The mean scores of decision making for groups of self-efficacy (high, average and low) were different.

- The mean scores of high Self-efficacy group were higher than the Average Self-efficacy group.

- The mean scores of high Self-efficacy group were higher than the low Self-efficacy group.

- $\quad$ The mean scores of decision making for two Self-efficacy groups (Average and Low) were equal.

- The mean scores of decision making for groups of Selfregulation (High, average and Low) were different.

- The mean scores of high Self-regulation group were higher than the Average Self-regulation group.

- The mean scores of high Self-regulation group were higher than the low Self-regulation group.

- The mean scores of Average Self-regulation group were higher than the low self-regulation group.

- The mean scores of decision making for groups of satisfaction of students with school (high, average and low) were different.

- The mean scores of high satisfaction of students with school group were higher than the average satisfaction of students with school group.

- The mean scores of high satisfaction of students with school group were higher than the low satisfaction of students with school group.

- The mean scores of average satisfaction of students with school group were higher than the low satisfaction of students with school group.

- The mean scores of decision making for twelfth graders due to interaction between Self-efficacy and Self-regulation were not different. The two variables may be treated as independent of each other.

- The mean scores of decision making for twelfth graders due to interaction between Self-efficacy and Satisfaction of students with school were different. 
- High SE, high SS (A1C1) and high SE, average SS (A1C2) of twelfth graders achieved equal mean scores on skill of decision making.

- High SE and average SS (A1C2) achieved higher mean scores on skill of decision making as compared to their counterparts high SE and low SS (A1C3).

- High SE and high SS (A1C1) scored higher means on skill of decision making as compared to their counterparts high SE and low SS (A1C3).

- Mean scores of average SE, high SS (A2C1) and average SE, average SS (A2C2) of twelfth graders on skill of decision making were not different.

- Average SE, average SS (A2C2) and average SE, low SS (A2C3) of twelfth graders achieved equal mean scores on skill of decision making.

- Average SE and low SS (A2C1) were higher on mean scores for skill of decision making as compared to their counterparts average SE and low SS (A2C3).

- Low SE and high SS (A3C1) achieved higher mean scores on skill of decision making as compared to their counterparts low SE and average SS (A3C2).

- Low SE, average SS (A3C2) and low SE, low SS (A3C3) of twelfth graders achieved equal mean scores on skill of decision making.

- Low SE and high SS (A3C1) scored higher mean scores on skill of decision making as compared to their counterparts low SE and low SS (A3C3).

- Mean scores of high SE, high SS (A1C1) and average SE, high SS (A2C1) of twelfth graders on skill of decision making were not different.

- Mean scores of average SE, high SS (A2C1) and low SE, high SS (A3C1) of twelfth graders on skill of decision making were not different.

- Mean scores of high SE, high SS (A1C1) and low SE, high SS (A3C1) of twelfth graders on skill of decision making were not different.

- High SE and average SS (A1C2) scored higher mean scores on skill of decision making as compared to their counterparts average SE and average SS (A2C2).

- Mean scores of average SE, average SS (A2C2) and low SE, average SS (A3C2) of twelfth graders on skill of decision making were not different.

- High SE and average SS (A1C2) achieved higher mean scores on skill of decision making as compared to their counterparts low SE and average SS (A3C2).

- Mean scores of high SE, low SS (A1C3) and average SE, low SS (A2C3) of twelfth graders on skill of decision making were not different.

- Mean scores of average SE, low SS (A2C3) and low SE, low SS (A3C3) of twelfth graders on skill of decision making were not different.

- Mean scores of high SE, low SS (A1C3) and low SE, low SS (A3C3) of twelfth graders on skill of decision making were not different.

- The mean scores of decision making for twelfth graders due to interaction between self-regulation and satisfaction of students with school were not different. The two variables may be treated as independent of each other.

- The mean scores of decision making for twelfth graders due to interaction between self-efficacy, self-regulation and satisfaction of students with school were different.
- High SE, high SR, high SS (A1B1C1) and high SE, high SR, average SS (A1B1C2) of twelfth graders achieved equal mean scores on skill of decision making.

- High SE, high SR, high SS (A1B1C1) achieved higher mean scores on skill of decision making as compared to their counterparts high SE, high SR and low SS (A1B1C3).

- High SE, high SR, average SS (A1B1C2) scored higher means on skill of decision making as compared to their counterparts high SE, high SR and low SS (A1B1C3).

- High SE, average SR, high SS (A1B2C1) and high SE, average $S R$, average SS (A1B2C2) of twelfth graders achieved equal mean scores on skill of decision making.

- High SE, average SR, high SS (A1B2C1) was higher on mean scores for skill of decision making as compared to their counterparts high SE, average SR and low SS (A1B2C3).

- High SE, average SR, average SS (A1B2C2) and high SE, average SR, low SS (A1B2C3) of twelfth graders achieved equal mean scores on skill of decision making.

- High SE, low SR, high SS (A1B3C1) and high SE, low SR, average SS (A1B3C2) of twelfth graders achieved equal mean scores on skill of decision making.

- High SE, low SR, high SS (A1B3C1) and high SE, low SR, low SS (A1B3C3) of twelfth graders achieved equal mean scores on skill of decision making.

- High SE, low SR, average SS (A1B3C2) and high SE, low SR, low SS (A1B3C3) of twelfth graders achieved equal mean scores on skill of decision making.

- Average SE, high SR, high SS (A2B1C1) achieved higher mean scores on skill of decision making as compared to their counterparts Average SE, high SR, average SS (A2B1C2).

- $\quad$ Average SE, high SR, high SS (A2B1C1) was higher on mean scores for skill of decision making as compared to their counterparts Average SE, high SR and low SS (A2B1C3).

- Average SE, high SR, average SS (A2B1C2) and Average SE, high SR, low SS (A2B1C3) of twelfth graders achieved equal mean scores on skill of decision making.

- $\quad$ Average SE, average SR, high SS (A2B2C1) and Average $\mathrm{SE}$, average $\mathrm{SR}$, average SS (A2B2C2) of twelfth graders achieved equal mean scores on skill of decision making.

- Average SE, average SR, high SS (A2B2C1) and Average SE, average SR, low SS (A2B2C3) of twelfth graders achieved equal mean scores on skill of decision making.

- Average SE, average SR, average SS (A2B2C2) and Average $\mathrm{SE}$, average SR, low SS (A2B2C3) of twelfth graders achieved equal mean scores on skill of decision making.

- Average SE, low SR, high SS (A2B3C1) and Average SE, low $\mathrm{SR}$, average SS (A2B3C2) of twelfth graders achieved equal mean scores on skill of decision making.

- Average SE, low SR, high SS (A2B3C1) and Average SE, low $S R$, low SS (A2B3C3) of twelfth graders achieved equal mean scores on skill of decision making.

- $\quad$ Average SE, low SR, average SS (A2B3C2) and Average SE, low SR, low SS (A2B3C3) of twelfth graders achieved equal mean scores on skill of decision making.

- Low SE, high SR, high SS (A3B1C1) was higher on mean scores for skill of decision making as compared to their counterparts low $\mathrm{SE}$, high $\mathrm{SR}$, average SS (A3B1C2).

- Low SE, high SR, high SS (A3B1C1) scored higher means scores on skill of decision making as compared to their counterparts low SE, high SR and low SS (A3B1C3). 
- Low SE, high SR, average SS (A3B1C2) and low SE, high SR, low SS (A3B1C3) of twelfth graders achieved equal mean scores on skill of decision making.

- Low SE, average SR, high SS (A3B2C1) and low SE, average $\mathrm{SR}$, average SS (A3B2C2) of twelfth graders achieved equal mean scores on skill of decision making.

- Low SE, average SR, high SS (A3B2C1) and low SE, average SR, low SS (A3B2C3) of twelfth graders achieved equal mean scores on skill of decision making.

- Low SE, average SR, average SS (A3B2C2) and low SE, average SR, low SS (A3B2C3) of twelfth graders achieved equal mean scores on skill of decision making.

- Low SE, low SR, high SS (A3B3C1) was higher on mean scores on skill of decision making as compared to their counterparts low SE, low SR, average SS (A3B3C2).

- Low SE, low SR, high SS (A3B3C1) was higher on mean scores for skill of decision making as compared to their counterparts low SE, low SR, low SS (A3B3C3).

- Low SE, low SR, average SS (A3B3C2) and low SE, low SR, low SS (A3B3C3) of twelfth graders achieved equal mean scores on skill of decision making.

Only these primary combination groups were considered relevant for the present study therefore t-ratio for only these groups were interpreted.

\section{Discussion of Results}

The results of the present investigation revealed that students with high, average or low self-efficacy did not achieve equal means on skill of decision making. The present study provides sufficient evidence to reject the hypothesis Ho. 1 which states that twelfth graders having high, average and low self-efficacy will not be significantly different on scores of skill of decision making. It can be concluded that self-efficacy is contributory for the improvement of skill of decision making.

The present study provides sufficient evidence to reject the hypothesis Ho.2. This states that twelfth graders having high, average and low self-regulation will not be significantly different on scores of skill of decision making. It can be concluded that selfregulation is contributory for the improvement of skill of decision making. This skill is related to planning and managing strategies which is the core component of self regulation skill. Most of the studies have suggested that self- regulation of the students must be developed to cope up with difficult situations of life.

The present study provides sufficient evidence to reject the hypothesis Ho. 3 which states that twelfth graders having high, average and low satisfaction of students with school will not significantly different on scores of skill of decision making. It can be concluded that satisfaction of students with school is contributory for the improvement of skill of decision making.

In present study the results did not support that interaction effect of self-efficacy and self-regulation has significant effect on skill of decision making. It was found that students with interaction effect of self-efficacy and self-regulation did not perform different on these skills. It can be concluded that interaction effect of self-efficacy and self-regulation is not found contributory for the improvement of skill of decision making.

The data of the present study revealed that self-efficacy and satisfaction of students with school did not operate independent of each other for skill of decision making. This means that these life skills seem to have been affected by the interaction of these two variables under study.
The results of the present study revealed that the self-regulation and satisfaction of students operated independent of each other for skill of decision making. In the course of present study, the interaction Ho. 6 were not rejected. This means that skill of decision making did not seem to be affected by the interaction of the two variables under study. It can be concluded that interaction effect of self-regulation and satisfaction of students with school is not found contributory for the improvement of skill of decision making.

The results of the present study revealed that the self-efficacy, self-regulation and satisfaction of students with school did not operate independent of each other for skill of decision making. This means that skill of decision making seem to have been affected by the interaction of all the three variables under study. As it was found out that interaction of self-efficacy, self-regulation and satisfaction of students with school is proved to be beneficial for the improvement skill of decision making and related activities which are needed to live successful and smooth life and to make accurate decision in the life.

\section{References}

Ahuja, M., \& Suman (2016). Effect of online Mastery Learning on life skills in relation to Self-regulation and Self-esteem. UnPublished Ph. D. thesis, Punjab University, Chandigarh.

Bandura, A (1997). In the science of Personality, by Pervin, L.A, 1996.

Bandura, A. (1988). Self-regulation of motivation and action through goal systems. In V. Hamilton, G. H. Bower, \& N. H. Frijda (Eds.), cognitive perspectives on emotion and motivation. pp.37-61. Dordrecht,Netherlands: KluwerAcademic.

Bandura, A. (1977). Self-Efficacy toward a unifying theory of behavioral change. Psychology Review 84(2), p191-215.

Bandura, A. (1982). Self-efficacy mechanisms in human agency. American Psychologist, 37, 122-147.

Bandura, A. (1986). Social Foundations of Thought and Action: A social Cognitive Theory, Prentise-Hall.

Boekaerts, M. (1997). Self-regulated learning: A new concept embraced by researchers, policy makers, educators, teachers, and students. Learning and Instruction, 7(2), 16-186.

Brown, B. B., \& Lohr, M. J. (1987). Peer-group affiliation and adolescent selfesteem: An integration of ego-identity and symbolic-interaction theories. Journal of Personality and Social Psychology, 52, 47-55.

Butler, D., \& Winne, P. (1995). Feedback and self-regulated learning: A theoretical synthesis. Review of Educational Researches, 65, 245-281.

Casey, A. C. (1989). Academic intramurals: The thrill of victory--The excitement of competition. (ERIC Document Reproduction Service No. ED322574).

Coie, J., Terry, R., Lenox, K., Lochman, J., \& Hyman, C. (1995). Childhood peer rejection and aggression as predictors of stable patterns of adolescent disorder. Development and Psychopathology, 7, 697713.

Decharms, R. (1968). Personla Causation. New York: Academic press

Decharms, R. (1976). Enhancing motivation. New York: Irvington publishers

Delors, J. (1996). Learning: The Treasure Within. Report of the UNESCO of the International Commission on Education for the Twenty First Century, UNESCO, Paris, p.141-142.

Epstein, J. L. (1981). The quality of school life. Lexington, Mass: D.C. Heath. Fraser, B. (1981). Validity and use of individualized classroom environment questionnaire. Paper presented at the Annual Meeting of Americal Educational Research Association, Los Angeles.

Evans, J. S. T., Barston. J. L., \& pollard. P. (1983). On the conflict between Logic and Belief in syllogistic reasoning. Memory and cognition, 11(3), 295-306.FICCI (2003)www.ficci.com.

Ferrari, J. R., \& Parker, J. T. (1992). High school achievement, self-efficacy, and locus of control as predictors of freshman academic performance. Psychological Reports 71 (2): 515-518.

Julinsson E. R., karlson, N., \& Garling, T. (2005). Weighing the past and the future in decision making. European Journal of Cognitive Psychology, 17 (4), 561-575. 
Lindley, L. D., \& Borgen, F. H. (2002). Generalized self-efficacy, Hallend theme self-efficacy and academic performance. Journal of career assessment 10 (3): 301-314.

Loukas, A. \& Robinson S. (2004). Examining the Moderating Role of Perceived School Climate in Early Adolescent Adjustment. Journal of Research on Adolescents, 14, 209-233.

Melnick, M. J., Sabo, D. F., \& Vanfossen, B. (1992). Educational effects of interscholastic athletic participation on African-American and Hispanic youth. Adolescence, 27(106), 295-308.

Mijanovich, T., \& Weitzman, B. C. (2003). Which "broken windows" matter? School, neighborhood, and family characteristics associated with youths' feelings of unsafely. Journal of Urban Health: Bulletin of the New York Academy of Medicine, 80, 400-415.

Mincemoyer, C., Perkins, D. F., \& Munyua, C. (2001). Youth Life Skills Evaluation project at Penn State. Retrieved on 10-1-2011 from http://www. pear web. org/ atis/tools/34

Multon, K. D., Brown, S. D., \& Lent, R. W. (1991). Relation of self-efficacy beliefs to academic outcomes: A meta-analytic investigation. Journal of counseling Psychology 38 (1): 30-38.

Myers, I. B. (1962). Gifts Differing: Understanding Personality Type. Mountain View, CA, Davies-Black publishing.

Pajares, F. (1996). Self-Efficacy beliefs in academic settings. Review of educational research 66 (4): 543-578.

Parker, J. E., \& Johnson, C. E. (1981). Affecting achievement motivation. (ERIC Document Reproduction Service No. ED336833).

Rasmussen, K. (1999-2000). The changing sports scene. Educational Leadership, 57(4), 26-29.

Richter, F. D., \& Tjosvold, D. (1980). Effects of Student participation in classroom decision making on attitudes, peer interaction, motivation, and learning. Journal of Applied psychology, 65, 74-80.

Sagi, A. \& Friedland, N. (2007). The cost of Richness: The Effect of the Size and Diversity of decision sets on post-Decision Regret. Journal of Personality and Social Psychology, 93(4) 515-524, DOI:10.1037/00223514.93.4.515.

Schimtt, N. and Lohar, B. (1987). Examiners Manual, Nebraska: National Association of Secondary School Principal.

Schunk, D. H. (1984). Enhancing Self-Efficacy and achievement through rewards and goods: Motivational and informational effects. Journal of Educational Research, 78, 29-34.

Schunk. D. H. (1991). Efficacy and academic motivation. Educational Psycho list 26, 207-231.

Schunk, D. H. \& Gunn, T. P. (1986). Self-efficacy and skill development:
Influence of task strategies and attribution. Journal of Educational Research, vol. 79, p. 238-244.

Schwarzer, R., \& Jerusalem, M. (1993). General Self-Efficacy Scale. Retrieved from http://wik.ed.uiuc.edu/ index.php/Self-efficacy.

Stipek, D. (2006). Relationship Matter. Educational Leadership, 64 (1), 46-49.

Taylor, R. G. (1965). Personality traits and discrepant achievement: a review. Journal of Counseling Psychology,vol.11, PP.76-81.

The International Bureau of Education (2006). Definition of life skills. In Manual for integrating HIV and AIDS education in school curricula TOOL 7 - Assessment of learning outcomes. UNESCO - Geneva.

The Samaritans, The Kelly Support Group \& Outward Bound Hong Kong (1999). Life skills foundation A social service, organization. www. lifeskills.stl.org.com.

Toda, S. (1979). Complex human behavior. New York: Holt, Rinrhart and Winston in John, A Michon; Eijkman, G.J. and Deklerk F. Len (1983). Handbook of Psychonomics, oxford: North Holland Publishing Company, vol.2.

Wang, M. C., \& Stiles, B. (1976). An investigation of Children's concept of self-responsibility for their school learning. American Educational Research journal, 13,159-179.

Wigfield, A. \& Eccles, J. (1992). The development of achievement task values: A theoretical analysis. Dev. Rev. 12:265-310.

William W. (1964). Stanaly, Educational Administration in Secondary Schools. Task \& challenge, Holt, Rechart, Winston.

World Health Organization. Life skills education for children and adolescents in schools, 1997. [On-line]. Available at: ttp://whqlibdoc.who.int/ hq/1994/WHO_MNH_PSF_93.7 A_Rev.2.

Zimmerman, B.J. (2000). Social learning theory and cognitive constructivism. In I. E. Sigel, D. M. Brodzinsky, \& R. M. Golinkoff (Eds), New directions in piagetian theory and practice, (39-49). Hillsdale, NJ: Erlbaum.

Zimmerman, B. J. (1994). Dimensions of academic self-regulation: A conceptual framework for education. In D. H. Schunk and B. J. Zimmerman (Eds.), Self-regulation of learning and performance: Issues and educational applications. Pp. 3-22. Hillsdale, NJ: Erlbaum.

Zimmerman, B. J. (2002). Achieving self-regulation: The trial and triumph of adolescence. In F. Pajares \& T. Urdan (Eds.), Academic motivation of adolescents (pp. 1-28). Greenwich, CT: Information Age.

Zimmerman, B. J., \& Martinez-Pons, M. (1986). Development of a structured interview for assessing student use of self-regulated learning strategies. American Educational Research Journal, 23(4), 614-628.

Zimmerman, B. J., \& Martinez-Pons, M. (1988). Construct validation of a strategy model of student self-regulated learning. Journal of Educational Psychology, 80(3) 